EGU21-11207

EGU General Assembly 2021

(c) Author(s) 2021. This work is distributed under

the Creative Commons Attribution 4.0 License.

\title{
Assessing the effects of climate and land use land cover changes on recent carbon storage in terrestrial ecosystem using model-satellite approach over Wallonia, Belgium
}

\author{
Arpita Verma ${ }^{1}$, Louis Francois ${ }^{1}$, Ingrid Jacquemin ${ }^{1,2}$, Merja Tölle $^{3}$, Huan Zhang ${ }^{3}$, and Benjamin \\ Lanssens ${ }^{1}$ \\ ${ }^{1}$ University Of Liege, Astrophysics Geophysics and Oceanography, Belgium (arpita.verma@student.uliege.be) \\ ${ }^{2}$ University of Liege, Department of Environmental Sciences and Management, Belgium \\ ${ }^{3}$ Center for Environmental Systems Research, University of Kassel, Germany
}

The use of a dynamic vegetation model, CARAIB, to estimate carbon sequestration from land-use and land-cover change (LULCC) offers a new approach for spatial and temporal details of carbon sink and for terrestrial ecosystem productivity affected by LULCC. Using the remote sensing satellite imagery (Landsat) we explore the role of land use land cover change (LULCC) in modifying the terrestrial carbon sequestration. We have constructed our LULCC data over Wallonia, Belgium, and compared it with the ground-based statistical data. However, the results from the satellite base LULCC are overestimating the forest data due to the single isolated trees. We know forests play an important role in mitigating climate change by capturing and sequestering atmospheric carbon. Overall, the conversion of land and increase in urban land can impact the environment. Moreover, quantitative estimation of the temporal and spatial pattern of carbon storage with the change in land use land cover is critical to estimate. The objective of this study is to estimate the inter-annual variability in carbon sequestration with the change in land use land cover. Here, with the CARAIB dynamic vegetation model, we perform simulations using remote sensing satellitebased LULCC data to analyse the sensitivity of the carbon sequestration. We propose a new method of using satellite and machine learning-based observation to reconstruct historical LULCC. It will quantify the spatial and temporal variability of land-use change during the 1985-2020 periods over Wallonia, Belgium at high resolution. This study will give the space to analyse past information and hence calibrate the dynamic vegetation model to minimize uncertainty in the future projection (until 2070). Further, we will also analyse the change in other climate variables, such as $\mathrm{CO}_{2}$, temperature, etc. Overall, this study allows us to understand the effect of changing land-use patterns and to constrain the model with an improved input dataset which minimizes the uncertainty in model estimation. 